\title{
ASSESSMENT OF SOIL NUTRIENTS AND PHYSICO- CHEMICAL PARAMETERS IN THE REGION OF HIWARKHED VILLAGE OF AMRAVATI DISTRICT (MAHARASHTRA STATE), INDIA
}

\author{
Rajesh P. Ganorkar ${ }^{1, *}$, Harshali A. Hole ${ }^{1}$ and Dinesh A. Pund ${ }^{2}$ \\ ${ }^{1}$ Department of Chemistry, Mahatma Fule Art's, Commerce and Sitaramji Chaudhari Science \\ Mahavidyalaya, Warud, Dist.Amravati-444906 (M.S.) INDIA. \\ ${ }^{2}$ Jawaharlal Darda Engineering and Technology, Lohara, Yeotmal (M.S.) India. \\ *E-mail: rajesh.ganorkar@ rediffmail.com
}

\begin{abstract}
Soil sampling is perhaps the most vital step for any analysis since a very small fraction of the huge soil mass of field is used to analysis. Five samples were collected from the study area. (Farmers field). Hiwarkhed village of Amravati District (Maharashtra State), India was selected for the present investigation. The nutrients and physicochemical parameters of the soil like soil moisture, pH, Organic Carbon, Nitrogen, Phosphorous, Potassium, Copper, Magnesium, Electric Conductivity, Calcium ,Alkalinity, $\mathrm{CaCO}_{3}$ and Zinc were analyzed in the month of February 2016. It was found that there was a marked variation in physicochemical parameters of various soil samples in different farmer's field.
\end{abstract}

Keywords: Soil testing, Parameters, Hiwarkhed Village, Nutrients.

(C) RASĀYAN. All rights reserved

\section{INTRODUCTION}

The quality and health of soil determine agricultural sustainability and environmental quality which jointly determines plant, animal and human health. The status of available micronutrients in soils and their relationship with various physico-chemical properties have been attempted by several investigators $^{1,2}$. Khadke et.al. Reported soil analysis and its environmental impact on Nanded city of Maharashtra State. ${ }^{3}$ The impacts of industrial pollution on the ground water soil and plant have also been reported in our country and abroad ${ }^{4}$. Perveen et al. ${ }^{5}$ have studied micronutrient status of soils and their relationship with various physico-chemical properties. Soil testing must provide sufficient information on trace elements available in the virgin soil there by lead to a strategy of maintaining the health of the soil over many years, and making up the depletion by adding micro nutrient, to the soil by biological or mineral application $\mathrm{Ca}$ and $\mathrm{Mg}$ are very important elements for plants life. It is the most abundant mineral in soil. These are, however, required in comparatively small amount and are known as secondary nutrients ${ }^{6}$.

Soil Testing is well recognized as a sound scientific tool to assess inherent power of soil to supply plant nutrients. Five samples were collected from the Khedi village (Farmers Field) of Wraud Taluka in Amravati district belongs to (Maharashtra State), ${ }^{7}$ Mehraj A. Sheikh and Munesh Kumar studied the soils of two forest types i.e., oak (Quercusleucotrichophora A. Camus) and pine (Pinusroxburghii Sargent) were analyzed for physico-chemical properties and economic analysis ${ }^{8}$.Studies on soils location Rajura Bazar, in Warud Tehsil in Amravati parameters like soil moisture, pH, EC, Carbon, Calcium carbonate, TDS, Magnesium, Calcium ,Nitrogen, Copper, Potassium and Phosphorous content, were analyzed . The values of $\mathrm{pH}$ indicated that all samples of the soils are alkaline, all samples were containing moderate amount of available micronutrients. ${ }^{9}$ Physico-Chemical characteristic is based on various parameter like $\mathrm{pH}$, Conductivity, Total Organic carbon available, available Phosphorus $\left(\mathrm{P}_{2} \mathrm{O}_{5}\right)$ and available Potassium $\left(\mathrm{K}_{2} \mathrm{O}\right)$. This study lead us to the conclusion of the nutrient's quantity of soil of Shehra Taluka, Dist. 
Panchmahals, Gujarat State. Soil sampling is the most vital step for anisole analysis. Results show that overage all the villages of this Shehra Taluka have various parameters like EC, PH, OC, P, K. ${ }^{10}$ Nutrients Characteristics and Physico-Chemical Assessment of soil In Zatamziri Village of Warud Tehsil, Amravati District $^{11}$. Soil physico-chemical assessment and the influence of capacity of cation exchange of the soil in and around Chennai. ${ }^{12}$

Considerable research work has been done regarding the study of Nutrients and Physico-Chemical assessment of various types of soil in Maharashtra as well as in India ${ }^{13-15}$ but the investigation of nutrients and parameters of Soil of Hiwarkhed village in Amravati district in Maharashtra was still lacking.

\section{Study Area}

\section{EXPERIMENTAL}

Hiwarkhed is a small village in Morshi tehsil of Amravati district in Maharashtra State. This area is known for oranges and Turmeric, The sources of water for this area is of mainly well and it is located at border of Maharashtra and Madhya Pradesh

\section{Collection of Samples}

Soil samples were collected randomly at 0 to $15 \mathrm{~cm}$ and 15 to $30 \mathrm{~cm}$ depths with five plots (field), five samples from each plot (field) respectively, in well sterilized polythene pouches. Soil sample were collected from following Farmers fields.

i. $\quad$ Sample 1 (HAH-1) was collected from Shri Ajabrao K. Holey field.

ii. $\quad$ Sample 2 (HAH-2) was collected from Shri Dinesh S. Holey field.

iii. $\quad$ Sample 3 (HAH-3) was collected from Shri. Kisanrao N. Holey field.

iv. Sample 4 (HAH-4) was collected from Shri. Kisanrao N. Holey field.

v. Sample 5 (HAH-5) was collected from Shri. Kisanrao N. Holey field.

Table-1: Nutrients and Physico-Chemical assessment of Soil Samples.

\begin{tabular}{c|l|c|c|c|c|c}
\hline \multicolumn{7}{c}{ Analysis of Parameters. } \\
\hline S.No. & Parameters & HAH-1 & HAH-2 & HAH-3 & HAH-4 & HAH-5 \\
\hline 1 & Color & Black & Brownish & Greyish & Black & Black \\
\hline 2 & Moisture (\%) & 2.35 & 3.00 & 3.17 & 3.17 & 3.35 \\
\hline 3 & pH & 7.71 & 7.68 & 7.78 & 7.58 & 7.76 \\
\hline 4 & Organic Carbon (\%) & 0.77 & 0.67 & 0.96 & 1.19 & 1.38 \\
\hline 5 & Nitrogen & 539.0 & 469.0 & 672.0 & 812.0 & 966.0 \\
\hline 6 & Phosphorous ( Kg/ Hect) & 65.32 & 15.99 & 21.03 & 10.23 & 170.11 \\
\hline 7 & Potassium (Kg/Hect) & 728.99 & 430.89 & 1052.83 & 985.08 & 1371.26 \\
\hline 8 & Copper (ppm) & 4.7 & 3.98 & 4.14 & 8.04 & 7.0 \\
\hline 9 & Magnesium (\%) & 5.12 & 2.24 & 7.04 & 6.72 & 8.64 \\
\hline 10 & Electric Conductivity(Ms) & 0.18 & 0.15 & 0.16 & 0.23 & 0.25 \\
\hline 11 & Calcium (\%) & 41.2 & 44.8 & 42.0 & 43.6 & 47.2 \\
\hline 12 & Alkalinity (mg / ) & 150 & 300 & 250 & 200 & 450 \\
\hline 13 & CaCO $(\%)$ & 12.25 & 13.25 & 4.25 & 2.5 & 5.0 \\
\hline 14 & Zinc (ppm) & 1.38 & 0.40 & 0.68 & 0.5 & 4.48 \\
\hline
\end{tabular}

\section{Determination of Physical Parameters}

Reagents uses for this research work were AR grade and chemicals other than reagent are LR grade manufactured by S.D. fine, LOBA and Merck. The soil sample were dried for about $24 \mathrm{hr}$. and grinded more finely. In this work about fourteen physico-chemical parameters and nutrients of five soil samples were determined and results were also recorded. During collection, temperature of the sample was recorded.

Following methods were used for estimation of various parameters are: 
i. Determination of Moisture: by Weighting Method.

ii. Determination of $\mathrm{pH}$ : by Digital $\mathrm{pH}$ Meter

iii. Determination of Electric Conductance: by Conductometer

iv. Determination of Organic Carbon: by Titration Method

v. Determination of Magnesium (Mg): by EDTA Titration Method

vi. Determination of Calcium (Ca): by Titration Method.

vii. Determination of (Total Dissolved Solid) TDS: by TDS METER.

viii. Determination of Copper $(\mathrm{Cu})$ : by Atomic Adsorption Spectroscopy.

ix. $\quad$ Determination of Nitrogen $(\mathrm{N})$ : by Titration Method

x. Determination of Phosphorous (P): by Titration Method

xi. Determination of Potassium (K): by Flame Photometry

xii. Determination of Calcium Carbonate $\left(\mathrm{CaCO}_{3}\right)$ : by Titration Method

xiii. Determination of Color of Soil: by Viewing soil

\section{Color}

\section{RESULTS AND DISCUSSION}

The soil sample HAH-1, HAH-4 and HAH-5 were black in the color, sample HAH-2 is brownish in color\& HAH-3 is greyish in color.

\section{Moisture}

Moisture content value ranges from $1 \%$ - 7\%. It is clear from the result that Soil sample HAH-1, HAH-2, HAH-3, HAH-4, \& HAH-5 has only $2 \& 3.5 \%$ moisture respectively.

\section{pH}

pH was observing in the range 7.58 - 7.78. The Soil sample HAH-1, HAH-2, HAH-3, HAH-4 and HAH5 is slightly alkaline. To dig drains, to make out flows, sowing green crops, cow manure to burry plant wastes, to supply necessary amount of water, use of gypsum is need.

\section{Electric conductivity}

Electric conductance values ranged from less than $1.00 \mathrm{~ms}$. It is seen that soil sample HAH-1, HAH-2, HAH-3, HAH-4 and HAH-5 has approximate of electric conductance. Use organic manure as per recommendation.

\section{Organic carbon}

Organic carbon contents were recorded in the range $0.67-1.38 \%$. The soil sample HAH-1, HAH-2, has less Organic carbon as compare to HAH-3 and HAH-4, HAH-5 percentage of organic carbon.

\section{Nitrogen}

Nitrogen content in the soil sample ranged from 469.0 to $966.0 \mathrm{~kg} / \mathrm{hect}$. The soil sample HAH-1 and HAH-2 has approximate less content of Nitrogen as compare to HAH-3 has high content and HAH-4, HAH-5 has extreme high content of nitrogen.

\section{Phosphorous}

Available phosphorous content in the soil sample ranged from $10.23-170.11 \mathrm{~kg} / \mathrm{hect}$. The soil sample HAH-2 , HAH-3 and HAH-4 has less phosphorous and HAH -1 has approximate high phosphorous \& HAH-5 has extreme high phosphorous.

\section{Potassium}

Available potassium content in the soil sample ranged from $430.89-1371.26 \mathrm{~kg} / \mathrm{hect}$. The soil sample HAH-1, HAH-2 has less potassium content as compare to HAH-3, HAH-4 and HAH-5 has extreme high potassium content. 


\section{$\mathrm{CaCO}_{3}$}

Calcium carbonate $\left(\mathrm{CaCO}_{3}\right)$ content in the soil samples ranges form 2.5-13.25\% It is seen that HAH-1, HAH-2 have high amount of calcium carbonate as compare to HAH-4, HAH-3 andHAH-5 have approximate amount of calcium carbonate. To make drains, use of ironpyroroid, use of ferrous, sulphate, phosphoric acid, ammonium sulphate.

\section{Zinc}

Zinc content in soil sample ranges from $0.4-4.48 \mathrm{ppm}$. It is seen that HAH-1, HAH-5 have high amount of zinc and HAH-2 have less amount of zinc and HAH-3, HAH-4 have middle amount of zinc.

\section{Copper}

Copper content is soil sample ranges from 3.98 - 8.04It is seen that HAH-1, HAH-2, HAH-3, HAH-4, HAH-5, have high amount of copper.

\section{Calcium}

Calcium content in soil sample ranges from 41.2-47.2\% It is seen that HAH-1, HAH-2, HAH-3, HAH-4, HAH-5 have less amount of calcium. To supply 10 tons of gypsum per hectare by mixing with cattle manure.

\section{Magnesium}

Magnesium content in soil sample ranges from 2.24-8.64\% . It is seen that HAH-1, HAH-2, HAH-3, HAH-4, \& HAH-5 have less amount of magnesium. To magnesium sulphate 500 gm hectare.

\section{Alkalinity}

Alkalinity was observed in the range between 200- 450. It is seen that soil sample HAH-1, HAH-2, HAH-3, HAH-4 has less alkalinity as compared to HAH-5.

\section{CONCLUSION}

The soil samples HAH-1, HAH-2, HAH-3, HAH-4 and HAH-5 become middle alkali and to the pH of this soil is increasing order. Suggested the use of compost manure. The recommendation of to dig drains, to make out flows, sowing green crop, cow manure, to busy plant wastes to supply necessary amount of water use to gypsum. In the soil sample HAH-1, HAH-2, HAH-3, HAH-4 and HAH-5 the calcium become less then the recommendation of supply 10 tons of gypsum per hectare by mixing with cattle manure. In the soil sample HAH-1, HAH-2, HAH-3, HAH-4 \& HAH-5 the magnesium become less. Then recommendation of magnesium sulphate $500 \mathrm{gm} . /$ hectare. In the soil sample HAH-3 \& HAH-4 phosphorous is less to increase the crop quality phosphorus will be given through fertilizers. In the soil sample HAH-1 and HAH-2 the organic carbon is approximate high and nitrogen is approximate high, so there is no need to use organic carbon and nitrogen for this soil. But to increase more yield of crop by using carbon and nitrogen for this soil.

\section{ACKNOWLEDGEMENT}

The authors are thankful to Dr. D. V. Atkare, Principal,Mahatma Fule Art's, Commerce and Sitaramji Chaudhary Science Mahavidyalaya, Warud, Dist. Amravati and Non-teaching staff for providing necessary laboratory facility during this work. Mr. Jadhav, Sadhana Krushi Vigyan Kendra, Durgapur, Amravati for their valuable suggestions.

\section{REFERENCES}

1. M. Kumar and A. L. Babel, Indian Journal of Agricultural Science, 3, 97 (2011).

2. R. Methur and P. Sudan, J. Chem. Pharm. Res., 3(3), 290 (2011).

3. P. A. Khadke, A. B. Bhosle and V. B. Yennawar, Research Front, 1(1), 73(2013).

4. G. L. Maliwal, Poll. Res., 23(1), 169 (2004). 
5. S. Perveen, M. Tariq, J. K. Farmanullah and A. Hamid, Journal of Agriculture, 9(5), 467, (1993).

6. I. Iwai, Australian Journal Soil Resources, 11,153(1961).

7. R. P. Ganorkar and M. V. Pande, Indian Journal of Chemical Society, 92, 1026(2015).

8. A. S. Mehraj and M. Kumar, Journal of American Science, 6(2), 6(2010).

9. R. P. Ganorkar and P. G. Chinchmalatpure, International Journal of Chemical, Environmental and Pharmaceutical Research, 4(2\&3), 46(2013).

10. K. P. Patel, Indian Journal of Applied Research, 5(9), 466(2015).

11. R. P. Ganorkar, S. D. Gorde and S. R. Kondulkar, European Journal of Pharmaceutical and Medical Research, 2(4), 256(2015).

12. N. Raman and D. Sathiyanarayanan, Rasayan Journal of Chemistry, 2(4), 875 (2009)

13. A. A. Patil and D. V.Ahire, J. Chem. Bio. Phy. Sci. Sec. C, 3(1), 840(2013).

14. R. P. Ganorkar and P. G. Chinchmalatpure, Int. J. Chemical, Env. And Pharmaceutical Research, 4(2\&3), 46(2013).

15. R. P. Ganorkar and N.H. Khan, International Journal of Chemical and Pharmaceutical Analysis, 1(4), 190(2014).

[RJC-1665/2017] 